\title{
Effect of behavior change communication through health development army on optimal nutrition and health practice of pregnant women in Ambo district, Ethiopia: a cluster randomized controlled community trial
}

Mitsiwat Abebe Gebremichael ( $\sim$ mitseabe@gmail.com )

Ambo University College of Medicine and Public Health https://orcid.org/0000-0002-8055-2168

Tefera Belachew Lema

Jimma University College of Public Health and Medical Sciences

\section{Research Article}

Keywords: Optimal nutrition and health practices, BCC, Health Development Army, Pregnancy and Ambo, Ethiopia

Posted Date: January 19th, 2022

DOI: https://doi.org/10.21203/rs.3.rs-1145170/v1

License: (c) (1) This work is licensed under a Creative Commons Attribution 4.0 International License. Read Full License 


\section{Abstract}

Background:Pregnancy is such a critical phase in a woman's life, when mother's nutritional and health status at conception and throughout pregnancy plays a key role in determining her health and well-being, as well as that of her child. Therefore, the objective of the study was to investigate the effect of Behavior Change and Communication (BCC) through women development Army on optimal nutrition and health practices of pregnant women.

Methods: A cluster randomized controlled community trial (CRCCT) with baseline and end line measurements using quantitative data collection methods was conducted in Ambo district among 750 pregnant women aged 18-49 years (375 of control and 375 of intervention groups). Of which endpoint data were collected from 372 and 372 pregnant women in the intervention and control clusters, respectively. Pretested semi structured questionnaire was used to collect data. The intervention was started in July, 2018 and data collection for end line was started in October, 2018.

Descriptive statistics, chi-square test, bivariate and lastly multivariate binary logistic regressions analysis was used to control confounders. Statistical analyses were conducted primarily on intention-to-treat (ITT) basis and $p$ value $<0.05$ was used to declare statistical significance.

Result: The overall optimal nutrition and health practice among intervention group were $62.6 \%$, while among control group were $39.0 \%(p<0.0001)$.

Being in the intervention group, educational status, estimated time to reach health institution, knowledge about nutrition and health were found significantly associated with optimal nutrition and health practices in multivariable binary logistic regression analysis $(p<0.05)$.

Conclusions: Behavior change communication (BCC) through women development army is effective in improving optimal nutrition and health practices of pregnant women. Therefore, to improve optimal nutrition and health practices of pregnant women, BCC through health development Army is recommended.

Trial registration: Pan African Clinical Trial Registry: unique identification number for the registry is (PACTR201805003366358).

\section{Background}

Nutrition throughout life has a major effect on health. Mother's nutritional and health status at conception and throughout pregnancy plays a key role in determining her health and well-being, as well as that of her child(1). According to Essential Nutrition Actions (ENA) framework, optimal nutrition and health practice of pregnant women encompasses optimal quantity and quality of diet; essential micronutrient intake; diseases prevention and treatment practices and supportive life style and care (2-5).

Behavior change communication (BCC) is widely recognized as one of the main health promotion strategies. It is an interactive process of working with individuals and communities to develop communication strategies to promote positive behaviors, as well as create a supportive environment to enable them to adopt and sustain positive behaviors(6, 7).

Suboptimal diet that comprises inadequate intake of calories and other nutrients, combined with a heavy maternal workload, impacts adversely on the health of the mother, the developing foetus and the newborn(8). Pregnant women need at least one extra meal a day than usual, along with plenty of safe water. Consumption of iron-rich foods and iodized salt is also important (9) 
Naturally, the urge to eat more is experienced by nearly all pregnant women(10). Weight gain is a normal process during pregnancy, in average a woman should gain about $12.5 \mathrm{~kg}$ during pregnancy. Many women gain barely half this amount because of poor diets and heavy workloads $(4,9)$.

Malaria prevention and treatment, deworming treatment, sanitation facilities and practices are very important aspects of nutrition and health practices during pregnancy $(2,4)$. Minimizing heavy work load and reducing work hours enables energy-deficient women to reduce her energy expenditure. Nutrients are mobilized from maternal stores to produce breast milk and fetal nutrition, and pregnant woman is vulnerable to depletion of her nutrient stores if she does not decrease work load or not get enough rest during pregnancy $(3,5)$.

Women's status and women's education play pivotal roles in improving nutrition. In addition to benefiting their nutrition and health status, greater education among women paves the way to greater productivity, empowerment, and control of resources allowing them to make better choices that ultimately benefit the health and nutrition of children and families $(11,12)$. In some cultures, because of their status, women are less able to access resources and make decisions to improve their health and nutrition(13).

Studies were done in Ethiopia on dietary knowledge and practice and nutritional status of pregnant women. According to the institution based study done in Mettu Karl Hospital, Southwest Ethiopia, among pregnant women the prevalence of sub-optimal dietary practices was $22 \%(14)$. According to the study done in Gedeo zone, southern Ethiopia, in 2018 around one-third $(67.8 \%)$ of pregnant women had poor dietary practices(15).

Different researcher's shows socio demographic factors like Age, wealth index, residence, Size of farmland and illiteracy or low education are common factors affecting maternal nutrition and health status and similarly maternal and health service related factors like years at marriage, ANC visits, level of nutritional knowledge and food practices (consume additional food during pregnancy and variety of food from both animal and plant origins are common factors affecting nutrition and health practices of pregnant women(16-19).

This paper aims to apply the Health development Army (HDA) as a pivotal role of implementer on improving optimal nutrition and health practices of pregnant women based on ENA framework. To the best of our knowledge, there is no study done on the effect of BCC through women development army on optimal nutrition and health practices among pregnant women based on ENA framework. Thus, this study was aimed to investigate the effect of BCC through women development army on optimal nutrition and health practices among pregnant women in the study area.

\section{Methods And Materials}

\section{Study design, study period and setting}

A cluster randomized controlled community trial (CRCCT) with baseline and end line measurement was conducted from June 2018 to October 2018 among pregnant women in Ambo district of West Shoa Zone, Ethiopia. Ambo district is located in western part of Ethiopia $114 \mathrm{~km}$ from Addis Ababa, the capital of Ethiopia. Based on 2017 district health office, it has 37,454 and 6976 reproductive age group and pregnant women respectively(20).

\section{Sample size determination and study population}

The sample size was calculated using $\mathrm{G}$ power 3.1.9.2 program with a power of $80 \%$ for Fisher's exact test and precision of 5\%. According to Fekadu B et al., (2016) the proportion of dietary practice among pregnant women ( 1 ) $0.34 \%$ was used(21), effect size (h) of 0.3 and with the allocation ratio case to control (N2/N1) of 1, Proportion (p2) 0.65 was obtained. The calculated sample size was multiplied by design effect of two due to cluster sampling. 
Considering a $10 \%$ loss to follow up, the final sample size was 770 pregnant women (385 of controls and 385 of interventions group). The study population was pregnant women aged 18-49 years, pregnant with duration of gestation of 12-16 weeks and permanent residents (who lived in the study area for more than six months) of Ambo district of the selected clusters of kebele's (the smallest administrative units). Pregnant women who were mentally ill, unable to speak and hear and those with chronic diseases such as hypertension, diabetes, Tuberculosis and HIV/AIDS and those enrolled in intervention programs such as supplementary feeding or general food distribution as these intervention would have an impact on optimal nutrition and health practices and thus bias the results of the study were excluded from the study.

\section{Recruitment, randomization and intervention allocation}

A multi-stage sampling technique was used to select 770 study participants. The total Kebele's in the district were stratified into rural and urban areas. Simple random sampling (SRS) with the lottery method was used to select 12 Kebeles (2 urban and 10 rural) from the existing 39 kebeles (6 urban \& 33 rural). Each kebele's has its own Clusters. The study district was divided into 149 exclusive clusters. Then the number of clusters in each kebele's was listed and 48 clusters were selected from the total clusters available in the district. We have used proportionate stratified sampling method to obtain clusters from each Kebeles. Nonadjacent clusters were randomly selected from each kebele and categorized into intervention $(n=24)$ and control $(n=24)$ group to prevent information contamination. We prepared the list of clusters, we were conducted a lottery to assign treatments between the two groups (intervention (group A) and control (group B)) in 1:1 ratio. All eligible pregnant women in one cluster were enrolled in the same arm (either in the intervention or control arms). The unit of randomization was cluster and both intervention and control groups were available in the same kebele. Then the sample size was allocated based on proportional to size (PS) sampling technique. The households in the selected clusters with pregnant women were known from baseline information and followed for the study. Eligible households were selected using simple random sampling with computer generated random number among selected clusters of kebeles and proportional allocation was used. A family folder prepared by kebele's Health extension workers (HEWs) was used as sampling frame of household. After baseline data were collected from all 750 pregnant women, then these women were divided into randomized groups using a computerized random-number generator, and drawing lots (control $n=375$, intervention $=375$, ensuring a recruitment balance of $1: 1$ throughout the study). Health Extension workers working in selected district randomized the cluster, screened and enrolled the study participants.

Three people from intervention and three from control groups were excluded from the study due to reasons such as withdrawal from regular follow-ups and miscarriage. The study was completed with 744 people (Fig. 1).

\section{Blinding (masking)}

Allocation concealment is not possible due to the nature of the intervention. The participants, as well as the HDA, are aware of the intervention. However, both the participants and HDA was blinded to the study objectives. We have used objective and reliable outcomes, such as Knowledge, Attitude and practices on optimal nutrition and health and nutritional status, which are less prone to ascertainment bias. Field supervisors, were blinded to the outcome of interest and finally, we were blinded the data collectors for the intervention.

\section{Intervention}

To continue with intervention design the researchers started by recruiting Health Development Armies (HDA) by the guide of health extension workers. HDA were recruited from the Kebele's that was specified as an intervention groups. Health development armies were women from the same community (and who were already involved in community activities) and known in the government structures. 
After recruitment, HDA were received training based on the protocol developed by the principal investigator for a period of one week related to the key optimal nutrition and health practice message based on (ENA) framework, guidance for formative research on maternal nutrition and making a balanced plate for pregnant women in Bangladesh $(3,9,22)$. The training had both theoretical and practical demonstration. After successful training was given, HAD were used the standard guidelines to ensure the implementation of the intervention. This intervention (i.e. BCC message) was given to pregnant women by making pregnant women in groups (2 Women's of HDA for one cluster (i.e. in average one HDA women for 10 pregnant women) in their specified locality once in every two week for 1:00 up to 1:30 hour length on nonworking days and continued for 3 months. On average, one cluster in a kebele includes 20 pregnant women with total of 24 intervention clusters. Similarly 24 clusters were selected for the control group.

To avoid variability among HDA major assessment questions (checklist) were prepared by the researchers (incorporating both theory and skill) and further consensus was reached. In addition, the researchers and supervisors followed HDA closely during pretest and throughout intervention whether they deliver the intended message or not based on the intervention protocol. Those who had defect in delivering health and nutrition BCC message were identified and corrective measure was given immediately. HDA were given posters, broachers and pamphlets with appropriate pictures to be displayed and given to pregnant women in addition to theoretical and practical (demonstration skill).

The main components of the intervention associated with optimal nutrition and health practice were message on eating additional foods during pregnancy (increase meal frequency and portion size with gestational age), avoidance of sharing of food with others, eating a variety(diversified) of food from vegetable, fruit and animal sources, utilization of iodized salt, appropriate timing and storage of iodized salt, decrease consumption of iron-inhibiting foods, such as tea and/or coffee, with meals, decrease alcohol consumption, not avoiding important food during pregnancy (associated with taboos), importance of taking iron/folate during pregnancy for at least three months, sleep under an insecticide-treated bed net, seek treatment from Health institution if developed illness(priority for malaria and deworming), wash hands with soap during critical moments, drinking only treated water(if out of pipe water), utilization of health care services, reducing heavy workload, taking day rest, improving self-decision making in food and her own health and importance of obtaining support from the family/Community during pregnancy. Knowledge and Attitude towards optimal nutrition and health were assessed during each BCC session as well. Then, BCC was given based on the identified gaps and on locally available, acceptable and affordable foods. Each pregnant woman attended six BCC sessions during the intervention period. The intervention was started in July, 2018 for all pregnant women who were identified as intervention group. Nutrition and health BCC message was imparted to the pregnant women (intervention group) for a period of 3 months from July to September, 2018.

Pregnant women in the control groups did not receive the intervention but were exposed to the normal standard of the intervention obtained from health care system and from the community as usual. They were followed till the time frame of the intervention and received the same assessments as the intervention group.

\section{Data collection tools and procedures}

A semi structured questionnaire prepared in English language was used to collect data. The questionnaire was translated into two languages (Afan Oromo and Amharic) then back to English by language experts to keep its consistency. The questionnaire was pretested in Ginchi town which is nearby to Ambo district on 39(5\%) of the total sample size to identify any ambiguity, length, completeness, consistency and acceptability of questionnaire and some skip patterns were corrected before the real data collection.

Eight diploma nurses were recruited to collect data. Training was given to the data collectors on the objective and relevance of the study, confidentiality of information, respondent's right, informed consent and techniques of interview. 
The filled questionnaires were checked for consistencies and completeness daily by four supervisors who had BSc degree in Nursing and principal investigators on the spot. The questionnaire includes part one: socio-demographic and economic characteristics, Part two: maternal characteristics, Part three: Knowledge, Attitude and practices on nutrition and health of pregnant women. Questions related to Knowledge, Attitude and practices was adapted from essential nutrition action frame work and from a guide of formative research for promoting maternal nutrition $(3,5,17)$. Knowledge of pregnant women about nutrition and health practice was assessed by using 14 questions that were used to assess knowledge of pregnant women regarding optimal nutrition and health was adapted based on the recommendation of ENA message. A knowledge score was calculated for each participant based on the number of questions that were correctly answered in the knowledge assessing questions section. Each correct response was scored 1 and incorrect response scored 0 . Pregnant woman was considered to have poor knowledge about nutrition and health if she scored below the highest tertile (i.e. in the first and/or second tertile) and good knowledge about nutrition and health if she scored in the third tertile. Attitude towards nutrition and health practice was assessed by asking attitude eleven questions. When the pregnant women agreed for questions regarding attitude, she has a score of 2 points, for neutral a score of 1 point and if she respond disagree, scored 0 point following the Likert scale. Then, the total attitude score was determined for each pregnant woman by summing up the scores across the eleven attitudes related questions. Pregnant woman was considered to have unfavorable attitudes if she scored below the third tertile and favorable attitude if she scored in the third tertile.

The outcome variable Nutrition and health practice was measured based on ENA frame work and guidance of formative research for promoting maternal nutrition using questions of practice about the dietary quantity, dietary quality, micronutrient intake, disease prevention and treatment and supportive life style and care.

The respondents had asked to choose $\mathrm{Yes}=1$ or $\mathrm{No}=0$ answers by indicating whether each practice of nutrition and health were practiced or not. To determine the practice of the respondents, scores was computed for the practice variables. One point was allocated to a correct response for each questions and zero for incorrect response and was summed together, the sum of the total scores for the practice varied from ( 0 up to 20 points maximum score) for each respondent's answers for all 20 nutrition and health practice related questions and this score was converted to tertile. Pregnant woman was considered to have suboptimal nutrition and health practice if she scored below the third tertile and optimal nutrition and health practice if she scored in the third tertile. Baseline data were collected from all pregnant women $(n=750)$ from June 1-21, 2018 and end point data were collected from pregnant women $(n=744)$ in October, 2018.

\section{Data processing and analysis}

Data were checked manually for completeness and consistency during data collection before data entry. Then it was entered in to EPI data version 3.1 and exported to SPSS for windows version 21 for cleaning and analyses. The effect of intervention was measured at endpoint of follow up.

First, descriptive statistics like mean and Standard Deviation was done for continuous variable and frequency and percentage for categorical data. A chi-square test was performed to compare the baseline characteristics of the intervention and control groups.

Bivariate analysis was performed between nutrition and health practice during pregnancy and associated factors one at a time. Their odds ratios (OR) with 95\% confidence intervals $(\mathrm{Cl})$ and p-values was obtained. Factors that were significantly associated with nutrition and health practice of mothers during pregnancy at $p$-value $<0.25$ in bivariable analysis were entered to multivariate binary logistic regression. $p$-values at $<0.05$ was used to declare statistical significance. The Hosmer -Lemeshow goodness - of - fit statistic is used to assess model goodness of fit. Multicollinearity was checked using Variance Inflation Factors (VIF) and there was no Multicollinearity between 
independent variables. Statistical analyses were conducted primarily on intention-to-treat (ITT) basis which is appropriate for a cluster randomized design study data analysis.

\section{Data quality control}

Training of data collectors \& supervisors was undertaken. Four supervisors who had BSc degree in Nursing and principal investigators supervised the HDA every two week. To reduce dropout and to increase adherence to the intervention and follow-up program, participants were informed of the importance to attend all sessions and act at their home according to the protocol delivered. Adherence to the BCC sessions was controlled by the HDA, and registered in a personal training diary (attendance sheet). The intervention process was pretested before the implementation of the trial. Pre-tested questionnaire was used to collect the data. Cronbatch's alpha value of knowledge and practice $>0.7$ for the whole scale of the instrument was obtained which make it fit for use in the study area. The questionnaire was also translated in to language spoken to the study area (Afan Oromo \& Amharic) to facilitate understanding of the respondents. Supervisors \& principal investigator were closely followed the data collection process. Filled questionnaires were checked daily for completeness and any other missing and errors were corrected.

\section{Ethical consideration}

This research is a community trial and it was registered on Pan African Clinical Trial Registry: unique identification number for the registry is (PACTR201805003366358), Confirmed time of registration 21 May 2018. Consolidated Standards of Reporting Trials (CONSORT) guideline was used for reporting the results (S1 additional file 2). The study protocol was reviewed and approved by the Jimma University Ethical Review Committee (ref No: RPGC/40724/2016). Permission was granted from the West Shoa Zonal and Ambo district health offices to conduct the study in the respective Kebele's. The nature of the study was fully explained to the study participants to obtain their written informed consent prior to participation in the study and all information obtained was kept anonymous. Password protection of soft copy data and use of key and lock for hard copy data was employed to guarantee confidentiality. Personally identifiable information will not be used in the presentation of the findings in any form.

\section{Results}

From a total of 770 assessed for eligibility, 20 pregnant women declined to participate (Fig. 1). A total of 750 were randomized to either the intervention $(n=375)$ or the control group $(n=375)$. Three women in the intervention and three in the control group were lost to follow-up because they developed miscarriage and withdraw from the study. A total of 744 participants were included in the study for analysis (372 in the intervention and 372 in the control groups) (Fig. 1). The total follow up period was three months and the follow-up started from July, 2018 to September, 2018.

At baseline approximately all participants' characteristics were similarly distributed between intervention and control groups. No significant difference was observed between the groups in terms of baseline characteristics like age, occupation (both respondents and husbands), educational status (both respondents and husbands), household size, wealth tertial and estimated time to reach health institution for service $(P>0.05)($ Table 1$)$. 
Table 1

Characteristics of pregnant women in control and intervention groups at the beginning of the study (Baseline participant characteristics), Ambo district, Ethiopia, 2018

\begin{tabular}{|c|c|c|c|c|}
\hline Variable & Category & $\begin{array}{l}\text { Intervention } \\
\text { group } \\
(\mathrm{n} 1=375)\end{array}$ & $\begin{array}{l}\text { Control } \\
\text { group } \\
(\mathrm{n} 2=375)\end{array}$ & $\mathbf{p}$ \\
\hline \multirow[t]{3}{*}{ Age of the respondent } & 18-24 Years & $92(24.5)$ & $88(23.5)$ & \multirow[t]{3}{*}{0.691} \\
\hline & 25-34 Years & $258(68.8)$ & $256(68.3)$ & \\
\hline & $>35$ Years & $25(6.7)$ & $31(8.3)$ & \\
\hline \multirow[t]{4}{*}{ Respondents' Occupation } & Employed & $19(5.1)$ & $21(5.6)$ & \multirow[t]{4}{*}{0.747} \\
\hline & $\begin{array}{l}\text { House wives/ Daily } \\
\text { laborers }\end{array}$ & $311(82.9)$ & 307 (81.9) & \\
\hline & Merchants & $23(6.1)$ & $19(5.1)$ & \\
\hline & Farmers & $22(5.9)$ & $28(7.5)$ & \\
\hline \multirow[t]{5}{*}{ Husband Occupation } & Employed & $38(10.1)$ & $44(11.7)$ & \multirow[t]{5}{*}{0.842} \\
\hline & Merchants & $43(11.5)$ & $39(10.4)$ & \\
\hline & Farmers & $227(60.5)$ & $230(61.3)$ & \\
\hline & Daily laborers & $39(10.4)$ & $32(8.5)$ & \\
\hline & Private workers & $28(7.5)$ & $30(8)$ & \\
\hline \multirow[t]{5}{*}{ Women educational status } & No formal education & $146(38.9)$ & $140(37.3)$ & \multirow[t]{5}{*}{0.563} \\
\hline & 1-4 Grade & $85(22.7)$ & $94(25.1)$ & \\
\hline & 5-8 Grade & $94(24.0)$ & $90(25.1)$ & \\
\hline & 9-12 Grade & $40(10.7)$ & $34(9.1)$ & \\
\hline & Diploma and higher & $10(2.7)$ & $17(4.5)$ & \\
\hline \multirow[t]{5}{*}{ Husband educational status } & No formal education & $114(30.4)$ & $105(28.0)$ & \multirow[t]{5}{*}{0715} \\
\hline & 1-4 Grade & $72(19.2)$ & $68(18.1)$ & \\
\hline & 5-8 Grade & $96(25.6)$ & $93(24.8)$ & \\
\hline & 9-12 Grade & $69(18.4)$ & $77(20.5)$ & \\
\hline & Diploma and higher & $24(6.4)$ & $32(8.5)$ & \\
\hline \multirow[t]{3}{*}{ Household size } & 1-3 house hold size & $116(30.9)$ & $97(25.9)$ & \multirow[t]{3}{*}{0.141} \\
\hline & 4-5 house hold size & $179(47.7)$ & $178(47.5)$ & \\
\hline & $>5$ house hold size & $80(21.3)$ & $100(26.7)$ & \\
\hline \multirow[t]{3}{*}{ Household wealth tertile } & Low & $111(29.6)$ & $108(28.8)$ & \multirow[t]{3}{*}{0.934} \\
\hline & Medium & $162(43.2)$ & $167(44.5)$ & \\
\hline & High & $102(27.2)$ & $100(26.7)$ & \\
\hline
\end{tabular}




\begin{tabular}{|c|c|c|c|c|}
\hline Variable & Category & $\begin{array}{l}\text { Intervention } \\
\text { group } \\
\text { (n1=375) }\end{array}$ & $\begin{array}{l}\text { Control } \\
\text { group } \\
\text { (n2=375) }\end{array}$ & p \\
\hline \multirow{3}{*}{$\begin{array}{l}\text { Estimated time to reach health } \\
\text { institution }\end{array}$} & $<30$ minutes & $79(21.1)$ & $77(20.5)$ & \multirow[t]{3}{*}{0.981} \\
\hline & $30-60$ minutes & 148 (39.5) & $148(39.5)$ & \\
\hline & $>60$ minutes & $148(39.5)$ & $150(40.0)$ & \\
\hline
\end{tabular}

\section{Knowledge on optimal nutrition and health}

Participants who had good knowledge on optimal nutrition and health proportion were almost the same between intervention groups $(30.9 \%)$ and control group (35.7\%) at baseline measurements. However, at endpoint of study period, participants who had god knowledge on optimal nutrition and health among intervention group were $53.2 \%$, while among control group were $39.0 \%(p<0.0001)$ (Fig. 2).

\section{Attitude on optimal nutrition and health}

Similarly, participants who had positive attitude towards optimal nutrition and health proportion were almost the same between intervention group (32.5\%) and control group (30.1\%) at baseline. However, at endpoint of study period, participants who had positive attitude towards optimal nutrition and health among intervention group were $43.3 \%$, while among control group were $28.8 \%(p<0.0001)$ (Fig. 3).

Specific nutrition and health practices

\section{Quantity of food}

There was no significance difference at base line measurement between control and intervention group in quantity of food related issues during this pregnancy $(p>0.05)$. However, there was a significant difference in the consumption of additional food during pregnancy ( $44.1 \%$ VS $68.5 \%, p<0.0001)$ and absence of sharing of food $(8.3 \%$ VS $27.2 \%$, $p<0.0001)$ at end point of the study as compared to intervention and control group respectively (Table 2 ).

\section{Quality of food}

There was no significance difference at base line measurement between control and intervention group related to quality of food ( $p>0.05)$. However, at the end point measurement, significant increase was seen in case of consumption of variety of food $(15.1 \%$ VS $29.0 \%, p<0.0001)$, utilization of lodized salt $(18.3 \%$ VS $50.8 \%, p<0.0001)$, appropriate utilization $(52.9 \%$ VS $86.2 \%, p<0.0001)$ and storage of iodized salt $(58.8 \%$ VS $81.4 \%, p<0.0001)$. Similarly there was significance decrease in avoidance of important food (because of taboos) during this pregnancy $(26.6 \%$ VS $10.0 \%$, $\mathrm{p}<0.0001$ ) at endpoint measurements between control and intervention group respectively (Table 2).

\section{Micronutrient supplements}

There was no significance difference at base line measurement between control and intervention group related to micronutrient intake ( $p>0.05)$. At the endpoint measurements, significance difference was observed in Iron/folate tablet supplementation at the endpoint measurements $(59.9 \%$ VS $81.5 \%, \mathrm{p}<0.0001)$ between control and intervention group respectively. However from this study, there was no significance difference between control and intervention group for duration of iron/folate supplementation ( $30.9 \%$ VS $34.0 \%, \mathrm{p}=0.622$ ) (Table 2 ).

\section{Disease prevention and treatment related practices}


There was no significance difference at base line measurement between control and intervention group related to disease prevention and treatment practices $(p>0.05)$. Significant difference was observed between control and intervention group in reporting any history of illness during this pregnancy $(64.5 \%$ VS $46.8 \%, p<0.0001)$, Number of pregnant women who started ANC visit $(62.4 \%$ VS $80.1 \%$, $p<0.0001)$, number of pregnant women who followed ANC at least 4 times $(15.1 \%$ VS $31.9 \%, p<0.0001)$ at the end point measurements. However, no significant difference was seen in the number of pregnant women who went health institution for help after developing illness (especially fever and parasitic related disease) $(40.8 \%$ VS $39.1 \%, p=0.719)$ and those pregnant women who drink only treated water during this pregnancy $(26.6 \%$ VS $32.8 \%, P=0.065)$ (Table 2$)$.

\section{Supportive life style and Care related practices}

At base line measurement, there was no significance difference observed between control and intervention group related to supportive life style and Care practices ( $>0.05$ ). Similarly, at endpoint of the study no significant difference was revealed by pregnant woman in decision making in food and her own health $(70.2 \% \mathrm{VS} 68.8 \%, p=0.691)$ and support from the family/community ( $89.2 \%$ VS $91.9 \%, p=0.209)$. However, significant difference was seen between control and intervention group in getting enough rest during this pregnancy $(73.4 \%$ VS $80.9 \%, p=0.014)$ (Table 2).

Generally, this study revealed that there was significance difference between control and intervention group in the overall optimal nutrition and health practices at the end point of the study(38.7\% VS 62.6\%, p<0.0001) (Table 2). 
Table 2

Nutrition and health related practices of pregnant women at baseline and endpoint among intervention and control groups, Ambo District, Ethiopia, 2018

\begin{tabular}{|c|c|c|c|c|c|c|c|}
\hline \multirow[t]{2}{*}{ Variable } & \multirow[t]{2}{*}{ Category } & \multicolumn{2}{|l|}{ Baseline } & \multirow[t]{2}{*}{$\mathbf{P}$} & \multicolumn{2}{|l|}{ End point } & \multirow[t]{2}{*}{$\mathbf{P}$} \\
\hline & & $\begin{array}{l}\text { Intervention } \\
\text { No (\%) }\end{array}$ & $\begin{array}{l}\text { Control } \\
\text { No (\%) }\end{array}$ & & $\begin{array}{l}\text { Intervention } \\
\text { No (\%) }\end{array}$ & $\begin{array}{l}\text { Control } \\
\text { No (\%) }\end{array}$ & \\
\hline \multicolumn{8}{|l|}{ Quantity of food } \\
\hline \multirow{2}{*}{$\begin{array}{l}\text { Ate additional } \\
\text { foods during this } \\
\text { pregnancy }\end{array}$} & No & $218(58.1)$ & $219(58.4)$ & \multirow[t]{2}{*}{0.941} & $117(31.5)$ & $208(55.9)$ & \multirow[t]{2}{*}{$<0.0001$} \\
\hline & Yes & $157(41.9)$ & $156(41.6)$ & & $255(68.5)$ & $164(44.1)$ & \\
\hline \multirow[t]{2}{*}{ Sharing of food } & No & $31(8.3)$ & $25(6.7)$ & \multirow[t]{2}{*}{0.612} & $101(27.2)$ & $31(8.3)$ & \multirow[t]{2}{*}{$<0.0001$} \\
\hline & Yes & $344(91.7)$ & $350(93.3$ & & $271(72.8)$ & $341(91.7)$ & \\
\hline \multicolumn{8}{|l|}{ Quality of food } \\
\hline \multirow[t]{2}{*}{ Ate variety of food } & No & 142(37.9) & $137(36.5)$ & \multirow[t]{2}{*}{0.706} & $264(71.0)$ & $316(84.9)$ & \multirow[t]{2}{*}{$<0.0001$} \\
\hline & Yes & $233(62.1)$ & $238(63.5)$ & & $108(29.0)$ & $56(15.1)$ & \\
\hline \multirow[t]{2}{*}{ kind of salt used } & Non iodized & $304(81.1)$ & $305(81.3)$ & \multirow[t]{2}{*}{0.926} & $183(49.2)$ & $304(81.7)$ & \multirow[t]{2}{*}{$<0.0001$} \\
\hline & lodized & 71(18.9) & $70(18.7)$ & & $189(50.8)$ & 68(18.3) & \\
\hline \multirow{2}{*}{$\begin{array}{l}\text { Added time of } \\
\text { iodized salt during } \\
\text { cooking of food }\end{array}$} & $\begin{array}{l}\text { Appropriately } \\
\text { utilized }\end{array}$ & $21(29.6)$ & $22(31.4)$ & \multirow[t]{2}{*}{0.813} & 163(86.2) & $36(52.9)$ & \multirow[t]{2}{*}{$<0.0001$} \\
\hline & $\begin{array}{l}\text { Inappropriately } \\
\text { utilized }\end{array}$ & $50(70.4)$ & $48(68.6)$ & & $26(13.8)$ & $32(47.1)$ & \\
\hline \multirow{3}{*}{$\begin{array}{l}\text { Method of storage } \\
\text { (If lodized) }\end{array}$} & Covered & $49(69.0)$ & $39(55.7)$ & \multirow[t]{3}{*}{0.158} & $153(81.4)$ & $40(58.8)$ & \multirow[t]{3}{*}{$<0.0001$} \\
\hline & Anywhere & $22(31.0)$ & $31(44.3)$ & & $35(18.6)$ & $28(41.2)$ & \\
\hline & un closed & & & & & & \\
\hline \multirow{2}{*}{$\begin{array}{l}\text { Food avoided } \\
\text { during this } \\
\text { pregnancy }\end{array}$} & No & $245(65.3)$ & $255(68.0)$ & \multirow[t]{2}{*}{0.439} & $334(90.0)$ & $273(73.4)$ & \multirow[t]{2}{*}{$<0.0001$} \\
\hline & Yes & $130(34.7)$ & $120(32.0)$ & & $37(10)$ & $99(26.6)$ & \\
\hline \multicolumn{8}{|l|}{$\begin{array}{l}\text { Micronutrient } \\
\text { supplements }\end{array}$} \\
\hline Supplemented & No & $159(42.4)$ & $165(44.0)$ & 0.670 & $69(18.5)$ & $149(40.1)$ & $<0.0001$ \\
\hline pregnancy & Yes & $216(57.6)$ & $210(56.0)$ & & $303(81.5)$ & $123(59.9)$ & \\
\hline Duration of & $<3$ months & $119(55.1)$ & $115(54.8)$ & 0.622 & $200(66.0)$ & $85(69.1)$ & 0.622 \\
\hline & $\geq 3$ months & $97(44.9)$ & $95(45.2)$ & & $103(34.0)$ & $38(30.9)$ & \\
\hline $\begin{array}{l}\text { Disease Prevention } \\
\text { and Treatment } \\
\text { practice }\end{array}$ & & & & & & & \\
\hline $\begin{array}{l}\text { History of illness } \\
\text { during pregnancy }\end{array}$ & No & 147(39.2) & $141(37.6)$ & 0.652 & 198(53.2) & 132(35.5) & $<0.0001$ \\
\hline
\end{tabular}




\begin{tabular}{|c|c|c|c|c|c|c|c|}
\hline \multirow[t]{2}{*}{ Variable } & \multirow[t]{2}{*}{ Category } & \multicolumn{2}{|l|}{ Baseline } & \multirow[t]{2}{*}{$\mathbf{P}$} & \multicolumn{2}{|l|}{ End point } & \multirow[t]{2}{*}{$\mathbf{P}$} \\
\hline & & $\begin{array}{l}\text { Intervention } \\
\text { No (\%) }\end{array}$ & $\begin{array}{l}\text { Control } \\
\text { No (\%) }\end{array}$ & & $\begin{array}{l}\text { Intervention } \\
\text { No (\%) }\end{array}$ & $\begin{array}{l}\text { Control } \\
\text { No (\%) }\end{array}$ & \\
\hline & Yes & $228(60.8)$ & $234(62.4)$ & & $174(46.8)$ & $240(64.5)$ & \\
\hline \multirow{2}{*}{$\begin{array}{l}\text { Seek treatment } \\
\text { from Health } \\
\text { institution }\end{array}$} & No & $137(60.1)$ & 138(59.0) & \multirow[t]{2}{*}{0.807} & $106(60.9)$ & $142(59.2)$ & \multirow[t]{2}{*}{0.719} \\
\hline & Yes & $91(39.9)$ & $96(41.0)$ & & 68(39.1) & $98(40.8)$ & \\
\hline \multirow{2}{*}{$\begin{array}{l}\text { Had ANC visit } \\
\text { (follow up) }\end{array}$} & No & $156(41.6)$ & 158942.1) & \multirow[t]{2}{*}{0.882} & $74(19.9)$ & $140(37.6)$ & \multirow[t]{2}{*}{$<0.0001$} \\
\hline & Yes & $219(58.4)$ & $217(57.9)$ & & 298(80.1) & $232(62.4)$ & \\
\hline \multirow{2}{*}{$\begin{array}{l}\text { Number of ANC } \\
\text { visit }\end{array}$} & $<4$ ANC visit & $161(73.5)$ & $156(71.9)$ & \multirow[t]{2}{*}{0.641} & $203(68.1)$ & 197(84.9) & \multirow[t]{2}{*}{$<0.0001$} \\
\hline & $\geq 4$ ANC visit & $58(26.5)$ & $61(28.1)$ & & $95(31.9)$ & $35(15.1)$ & \\
\hline \multirow{2}{*}{$\begin{array}{l}\text { Drink only treated } \\
\text { water }\end{array}$} & No & $275(73.3)$ & $270(72.0)$ & \multirow[t]{2}{*}{0.682} & $250(67.2)$ & $273(73.4)$ & \multirow[t]{2}{*}{0.065} \\
\hline & Yes & $100(26.7)$ & $105(28.0)$ & & $122(32.8)$ & $99(26.6)$ & \\
\hline \multicolumn{8}{|l|}{$\begin{array}{l}\text { Supportive life style } \\
\text { and Care }\end{array}$} \\
\hline \multirow[t]{2}{*}{ Had enough rest } & No & 105(28.0) & $101(26.9)$ & \multirow[t]{2}{*}{0.743} & $71(19.1)$ & $99(26.6)$ & \multirow[t]{2}{*}{0.014} \\
\hline & Yes & $270(72.0)$ & $274(73.1)$ & & $301(80.9)$ & $273(73.4)$ & \\
\hline \multirow{2}{*}{$\begin{array}{l}\text { Self-decision in the } \\
\text { household }\end{array}$} & No & $253(67.5)$ & $269(71.7)$ & \multirow[t]{2}{*}{0.204} & 116(31.2) & $111(29.8)$ & \multirow[t]{2}{*}{0.691} \\
\hline & Yes & $122(32.5)$ & $106(28.3)$ & & $256(68.8)$ & $261(70.2)$ & \\
\hline \multirow{2}{*}{$\begin{array}{l}\text { Support from the } \\
\text { family/Community }\end{array}$} & No & 109(29.1) & $102(27.2)$ & \multirow[t]{2}{*}{0.570} & $30(8.1)$ & 40(10.8) & \multirow[t]{2}{*}{0.209} \\
\hline & Yes & $266(70.9)$ & $273(72.8)$ & & $342(91.9)$ & $332(89.2)$ & \\
\hline \multirow{2}{*}{$\begin{array}{l}\text { Overall optimal } \\
\text { nutrition and } \\
\text { health practice }\end{array}$} & Suboptimal & $269(71.7)$ & $276(73.6)$ & \multirow[t]{2}{*}{0.566} & 139(37.4) & $228(61.3)$ & \multirow[t]{2}{*}{$<0.0001$} \\
\hline & Optimal & 106(28.3) & $99(26.4)$ & & $233(62.6)$ & 144(38.7) & \\
\hline
\end{tabular}

\section{Factors associated with optimal nutrition and health practices at endpoint of the study during pregnancy in Ambo} district

Study group (being in the intervention group), residence, age of the respondent, occupation of the respondents, occupation of the husband, respondent educational status, husband educational status, household size, gravida, number of Antenatal care visit, gestational age, estimated time to reach health institution, knowledge about nutrition and health and attitude towards nutrition and health were found significant at $\mathrm{p}$-value $<=0.25$ in bi-variate analysis. However, Study group (being in the intervention group), respondent educational status(being 5-8 grades), husband educational status (being secondary and above education), estimated time to reach health institution and knowledge about nutrition and health were found significantly associated with optimal nutrition and health practices in multivariable binary logistic regression analysis $(p<0.05)($ Table 3$)$.

Study group (being in the intervention group) was found to be significantly associated with optimal nutrition and health practices. Pregnant women who received intervention were 2 times higher odds of optimal nutrition and health practices compared to pregnant women who were in the control group (AOR=2.051,95\% Cl: 1.318-3.192). Respondent 
education (being 5-8 Grades) is significantly associated with optimal nutrition and health practices. Those pregnant women who attended 5-8 Grades were $52.6 \%$ less likely to practice optimal nutrition and health as compared to pregnant women who had no formal education (AOR=0.474, 95\% Cl: $0.231-0.974$ ). Similarly, husband education is significantly associated with optimal nutrition and health practices. Those pregnant women whose husbands had secondary and higher education were 3.152 times more likely odds of optimal nutrition and health practices compared with no formal education ( $\mathrm{AOR}=3.152,95 \% \mathrm{Cl}$ : 1.406-7.070). Estimated time to reach health institution was significantly associated with optimal nutrition and health practices. The study showed that odds of optimal nutrition and health practices among pregnant women who traveled 30-60 minutes and greater than 60 minutes to get care from health institution were $38.6 \%$ and $53.2 \%$ less likely as compared to pregnant women who travel less than 30 minutes $(A O R=0.614,95 \% \mathrm{Cl}: 0.342-1.104)$ and $(A O R=0.468,95 \% \mathrm{Cl}: 0.288-0.762)$ respectively. The study revealed that those pregnant women who had good knowledge on optimal nutrition and health were 2.187 times higher odds of optimal nutrition and health practices than their counter parts (AOR=2.187, 95\%Cl:1.356-3.528) (Table 3). 
Table 3

Bivariate and Multivariate binary Logistic Regression Analysis for factors associated with nutrition and health Practice among Pregnant women at endpoint in Ambo district, Ethiopia, 2018, $(n=744)$

\begin{tabular}{|c|c|c|c|c|c|c|}
\hline \multirow[t]{2}{*}{ Variable } & \multirow[t]{2}{*}{ Category } & \multicolumn{2}{|c|}{$\begin{array}{l}\text { Nutrition and Health } \\
\text { practice }\end{array}$} & \multirow[t]{2}{*}{$\begin{array}{l}\mathrm{COR}(95 \% \\
\mathrm{Cl})\end{array}$} & \multirow[t]{2}{*}{$\mathrm{AOR}(95 \% \mathrm{Cl})$} & \multirow[t]{2}{*}{ p-value } \\
\hline & & Optimal & Suboptimal & & & \\
\hline \multirow[t]{2}{*}{ Study group } & Control & 144 & 228 & 1 & 1 & \\
\hline & Intervention & 233 & 139 & $\begin{array}{l}2.654(1.974- \\
3.569)\end{array}$ & $\begin{array}{l}2.051(1.318- \\
3.192)\end{array}$ & 0.001 ** \\
\hline \multirow[t]{2}{*}{ Residence } & Rural & 282 & 321 & 1 & & \\
\hline & Urban & 95 & 46 & $\begin{array}{l}2.351(1.597- \\
3.461)\end{array}$ & $\begin{array}{l}1.585(0.770- \\
3.259)\end{array}$ & 0.211 \\
\hline \multirow[t]{3}{*}{ Age of the respondent } & 18-24 Years & 108 & 70 & 1 & 1 & \\
\hline & 25-34 Years & 246 & 267 & $\begin{array}{l}0.597(0.422- \\
0.845)\end{array}$ & $\begin{array}{l}0.828(0.442- \\
1.550)\end{array}$ & 0.555 \\
\hline & $>35$ Years & 23 & 30 & $\begin{array}{l}0.497(0.267- \\
0.925)\end{array}$ & $\begin{array}{l}1.377(0.429- \\
4.413)\end{array}$ & 0.591 \\
\hline \multirow{4}{*}{$\begin{array}{l}\text { Respondents' } \\
\text { Occupation }\end{array}$} & Employed & 29 & 12 & 1 & 1 & \\
\hline & House wives & 290 & 309 & $\begin{array}{l}0.388(0.194- \\
0.775)\end{array}$ & $\begin{array}{l}1.209(0.304- \\
4.806)\end{array}$ & 0.787 \\
\hline & $\begin{array}{l}\text { Merchants/ Daily } \\
\text { laborers }\end{array}$ & 37 & 17 & $\begin{array}{l}0.901(0.372- \\
2.181)\end{array}$ & $\begin{array}{l}2.479(0.495- \\
12.432)\end{array}$ & 0.270 \\
\hline & Farmers & 21 & 29 & $\begin{array}{l}0.300(0.125- \\
0.720)\end{array}$ & $\begin{array}{l}0.730(0.154- \\
3.458)\end{array}$ & 0.692 \\
\hline \multirow[t]{4}{*}{ Husband Occupation } & Employed & 61 & 22 & 1 & 1 & \\
\hline & Merchants & 46 & 34 & $\begin{array}{l}0.488(0.252- \\
0.943)\end{array}$ & $\begin{array}{l}0.431(0.129- \\
1.442)\end{array}$ & 0.172 \\
\hline & Farmers & 195 & 257 & $\begin{array}{l}0.274(0.162- \\
0.461)\end{array}$ & $\begin{array}{l}0.538(0.170- \\
1.705)\end{array}$ & 0.292 \\
\hline & $\begin{array}{l}\text { Daily laborers/ } \\
\text { Private workers }\end{array}$ & 75 & 54 & $\begin{array}{l}0.501(0.275- \\
0.913)\end{array}$ & $\begin{array}{l}0.437(0.137- \\
1.391)\end{array}$ & 0.161 \\
\hline \multirow[t]{4}{*}{$\begin{array}{l}\text { Respondent } \\
\text { educational status }\end{array}$} & $\begin{array}{l}\text { No formal } \\
\text { education }\end{array}$ & 113 & 169 & 1 & 1 & \\
\hline & 1-4 Grade & 85 & 93 & $\begin{array}{l}1.367(0.936- \\
1.996)\end{array}$ & $\begin{array}{l}0.760(0.414- \\
1.393)\end{array}$ & 0.374 \\
\hline & 5-8 Grade & 90 & 91 & $\begin{array}{l}1.479(1.015- \\
2.155)\end{array}$ & $\begin{array}{l}0.474(0.231- \\
0.974)\end{array}$ & $0.042^{*}$ \\
\hline & $\begin{array}{l}\text { Secondary and } \\
\text { above }\end{array}$ & 89 & 14 & $\begin{array}{l}9.508(5.157- \\
17.529)\end{array}$ & $\begin{array}{l}2.452(0.797- \\
7.545)\end{array}$ & 0.118 \\
\hline $\begin{array}{l}\text { Husband educational } \\
\text { status }\end{array}$ & $\begin{array}{l}\text { No formal } \\
\text { education }\end{array}$ & 82 & 134 & 1 & 1 & \\
\hline
\end{tabular}

Significant association ${ }^{* *} p<0.01,{ }^{*} p-$ value $<0.05$ 


\begin{tabular}{|c|c|c|c|c|c|c|}
\hline & 1-4 Grade & 56 & 84 & $\begin{array}{l}1.089(0.705- \\
1.684)\end{array}$ & $\begin{array}{l}1.306(0.682- \\
2.499)\end{array}$ & 0.421 \\
\hline & 5-8 Grade & 98 & 90 & $\begin{array}{l}1.779(1.197- \\
2.646)\end{array}$ & $\begin{array}{l}1.525(0.790- \\
2.946)\end{array}$ & 0.209 \\
\hline & $\begin{array}{l}\text { Secondary and } \\
\text { above }\end{array}$ & 141 & 59 & $\begin{array}{l}3.905(2.593- \\
5.883)\end{array}$ & $\begin{array}{l}3.152(1.406- \\
7.070)\end{array}$ & $0.005^{\star \star}$ \\
\hline \multirow[t]{3}{*}{ Household size } & 1-2 household & 63 & 38 & 1 & 1 & \\
\hline & 3-4 household & 149 & 126 & $\begin{array}{l}0.713(0.447- \\
1.138)\end{array}$ & $\begin{array}{l}0.762(0.371- \\
1.566)\end{array}$ & 0.459 \\
\hline & $>=5$ household & 165 & 203 & $\begin{array}{l}0.490(0.312- \\
0.770)\end{array}$ & $\begin{array}{l}0.795(0.343- \\
1.845)\end{array}$ & 0.594 \\
\hline \multirow[t]{3}{*}{ Gravida } & One Pregnancy & 136 & 92 & 1 & 1 & \\
\hline & 2-4 pregnancy & 166 & 187 & $\begin{array}{l}0.601(0.429- \\
0.841)\end{array}$ & $\begin{array}{l}1.210(0.638- \\
2.292)\end{array}$ & 0.560 \\
\hline & $>=5$ Pregnancy & 75 & 88 & $\begin{array}{l}0.577(0.384- \\
0.865)\end{array}$ & $\begin{array}{l}1.115(0.498- \\
2.496)\end{array}$ & 0.791 \\
\hline \multirow[t]{2}{*}{ Number of ANC visit } & $<4$ visit & 253 & 147 & 1 & 1 & \\
\hline & $>=4$ visit & 98 & 32 & $\begin{array}{l}1.779(1.137- \\
2.785)\end{array}$ & $\begin{array}{l}1.191(0.695- \\
2.042)\end{array}$ & 0.525 \\
\hline \multirow{3}{*}{$\begin{array}{l}\text { Estimated time to } \\
\text { reach Health Institution }\end{array}$} & $<30$ minutes & 96 & 59 & 1 & 1 & \\
\hline & $30-60 \mathrm{~min}$ & 141 & 153 & $\begin{array}{l}1.801(1.212- \\
2.679)\end{array}$ & $\begin{array}{l}0.614(0.342- \\
1.104)\end{array}$ & 0.103 \\
\hline & $>60 \mathrm{~min}$ & 140 & 155 & $\begin{array}{l}1.020(0.738- \\
1.410)\end{array}$ & $\begin{array}{l}0.468(0.288- \\
0.762)\end{array}$ & $0.002^{\star \star}$ \\
\hline \multirow{2}{*}{$\begin{array}{l}\text { Knowledge on nutrition } \\
\text { and health }\end{array}$} & Poor Knowledge & 141 & 260 & 1 & 1 & \\
\hline & Good Knowledge & 236 & 107 & $\begin{array}{l}4.067(2.992- \\
5.528)\end{array}$ & $\begin{array}{l}2.187(1.356- \\
3.528)\end{array}$ & $0.001 * *$ \\
\hline \multirow[t]{2}{*}{$\begin{array}{l}\text { Attitude on nutrition } \\
\text { and health }\end{array}$} & $\begin{array}{l}\text { Unfavorable } \\
\text { Attitude }\end{array}$ & 191 & 285 & 1 & 1 & \\
\hline & Favorable Attitude & 186 & 82 & $\begin{array}{l}3.385(2.463- \\
4.652)\end{array}$ & $\begin{array}{l}1.509(0.922- \\
2.469)\end{array}$ & 0.102 \\
\hline
\end{tabular}

\section{Discussion}

This study has documented effect of BCC on optimal nutrition and health practices based on Essential nutrition action (ENA) frame work among pregnant women in Ambo District, West Shewa Zone, Ethiopia. The finding of this study showed that pregnant women in the intervention group had good knowledge of optimal nutrition and health than the control group. This study is consistent with study done by Farnoush F, et al., 2013 in Iran and Lidia Ghirmai T, et al., 2021 in Asmara, Eritrea that nutrition education was significantly increase knowledge of pregnant women respectively $(23,24)$. Similarly, participants who were in the intervention group had positive attitude towards optimal nutrition and health than the control group. This study is in line with the study done among pregnant women in 
Indonesia that revealed providing nutrition and reproductive health education through small groups with interactive methods improves the attitudes of pregnant women(25).

To the best of our knowledge, this is one of the first cluster randomized controlled community trial (CRCCT) to evaluate the effect of BCC through health development Army on optimal nutrition and health practices. From this study, BCC had a significant effect on optimal nutrition and health practices in the intervention group compared with the control group. Even if difficult to compare with similar target group and topic, this is in line with cross-sectional study done in the Shabelle zone, Somali region of eastern Ethiopia that BCC bring change on infant and young child feeding (IYCF) practices. Result confirmed that in order to be effective BCC needs to be performed using health developmental armies to bridge the gap between knowledge and practice(26). This suggested that, BCC is an important tool to maintain behavior of pregnant women in improving optimal nutrition and health practices among pregnant women(27). Similarly, the study done in Indonesia, revealed that providing nutrition and reproductive health education improves the practices of pregnant women(25).

Our intervention also supported by health behavior change communication theory, the 'Integrative Model of Behavioral Prediction' which reported a strong intention of a person to perform a behavior, accompanied by the necessary skills and abilities to perform it, and under a conducive environment results in the expected behavior change(28). This behavior change communication message, other than theoretical aspect it also includes a practical demonstration (visual, interactive and skillful) and since its participatory nature engages the pregnant women involved on preparing a nutritionally diversified and balanced diet, motivated to take iron/folete, follow disease prevention and treatment practices and also a need of support from the family and community. Behavior change communication through health development Army is an affordable; does not require any food supplementation and suitable intervention since conducted at the community level to improve optimal nutrition and health practices of pregnant women and more likely to be sustainable in resource-poor settings including Ethiopia.

Moreover, this finding had an implication that following close and supportive supervision for health development armies by health professionals, who were used as an implementer of the intervention, resulted in improvement of optimal nutrition and health practices of pregnant women.

This study revealed that, those pregnant women who attended 5-8 Grades were less likely to practice optimal nutrition and health as compared to pregnant women who had no formal education. This finding is supported by the study done in Ghana that, those pregnant adolescents who did not go to school are more likely to be associated with good eating habits than those who attended school (29). Since it is difficult to give the possible reason there is a need for further studies to ascertain contributory factors.

According to this study, husband education is significantly associated with optimal nutrition and health practices. The likelihood of optimal nutrition and health practices increased as the education level of the husbands increased. This study is in congruent with the study done in Dakar, Senegal on factors influencing nutritional practices among mothers that husband education levels were positively correlated with nutritional practices of mothers(30). Similarly, this finding was consistent with study done in in Gedeo zone, southern Ethiopia on dietary practices and its determinant among pregnant women that revealed respondents husband with formal education were more odds of good dietary practice than those without formal education(15). This study also supported by the study done in Harar, Ethiopia; where the risk of malnutrition doubled among women with illiterate husband compared with those with literate husbands(31). This finding implies that husband educational attainment is clearly related to optimal nutrition and health practices of pregnant women. 
This finding revealed that the odds of optimal nutrition and health practices among pregnant women who traveled 3060 minutes and greater than 60 minutes to get care from health institution were less likely as compared to pregnant women who travel less than 30 minutes. This finding is consistent with the study done in Tigray, Ethiopia, that mothers reported the unavailability of health facilities close to their locality was a key barrier to utilizing available services from health institution(32). This has an implication that pregnant women are forced to either travel long distances to get health services or otherwise don't access the service given at health institution including nutrition and/or health related issues.

Moreover, in this study knowledge had shown significant association with optimal nutrition and health practice during pregnancy. This finding is supported by the study done in different parts of Ethiopia like Misha Woreda(33), Addis Ababa(34) and West Gojjam(35). The reason behind the similarity might be due to the fact that when women is knowledgeable on optimal nutrition and health, they may be aware of the consequences of suboptimal nutrition and health practice on their fetus, as well as on themselves, and they will more enforced to practice optimal nutrition and health related behaviors. This implies that, though knowledge is not behavior, it determines the practice through motivating mothers to make changes that could maximize optimal nutrition and health practices.

\section{Limitation}

This study acknowledges the following limitations; allocation concealment is not possible due to the nature of the intervention, however, both the participants and HDA was blinded to the study objectives.

Since there were no previous studies on this topic, these findings cannot be easily discussed on the overall optimal nutrition and health practices.

\section{Conclusions}

This study demonstrated that behavior change communication (BCC) through women development army is effective in improving optimal nutrition and health practices of pregnant women. Behavior change communication through health development Army is an affordable and suitable intervention to improve knowledge, Attitude and practices of optimal nutrition and health of pregnant women. Therefore, to improve optimal nutrition and health practices of pregnant women, BCC through health development Army is recommended.

\section{Abbreviations}

ANC

Antenatal Care

AOR

Adjusted Odd Ratio

BCC

Behavior Change Communication

$\mathrm{Cl}$

Confidence Interval

CONSORT

Consolidated Standards of Reporting Trials

COR

Crude Odd Ratio

CRCCT

Page $17 / 24$ 
Cluster Randomized Controlled Community Trial

EDHS

Ethiopian Demographic and Health Survey

ENA

Essential Nutrition Action

HAD

Health Development Army

HEW

Health Extension Worker

IYCF

Infant and Young Child feeding Practice.

\section{Declarations}

\section{Ethics approval and consent to participate}

The study protocol was reviewed and approved by the Jimma University Ethical Review Committee (ref No: RPGC/40724/2016). Permission was granted from the West Shoa Zonal and Ambo district health offices to conduct the study in the respective Kebele's. The nature of the study was fully explained to the study participants to obtain their written informed consent prior to participation in the study and all information obtained was kept anonymous. This trial was registered on Pan African Clinical Trial Registry: unique identification number for the registry is (PACTR201805003366358).

\section{Consent for publication}

Not applicable.

\section{Availability of data and materials}

All the data related to this research are available in the text, tables or figures.

\section{Competing interests}

The authors declare that they have no competing interests.

\section{Funding}

No funding source for this research

\section{Authors' contributions}

MA: conceived and designed the study, conducted statistical analysis and result interpretation, prepared manuscript. The author read and approved the manuscript. TB: conceived and designed the study, conducted statistical analysis and result interpretation, prepared manuscript. The author read and approved the manuscript.

\section{Acknowledgements}

The authors are grateful to West shoa zone and Ambo district personnel for providing permission to conduct the study, and as well as to the supervisor and data collectors who committed themselves throughout the study period. 
Our thanks also go to all authors those who have availed their published articles free of charge for our literature review. Finally, we would like to express our gratitude to all participants who voluntarily participated in the study

\section{References}

1. Black RE, Allen LH, Bhutta ZA. Maternal and Child Under nutrition Study Group. Maternal and child under nutrition: global and regional exposures and health consequences. Lancet 2008:24360((https://doi.org/10.1016/S0140-6736(08)60135-X).Access date October 10, 2020. 2008:243-60.

2. McClure EM, Goldenberg RL, Dent AE, Meshnick SR. A systematic review of the impact of prevention of malaria in pregnancy on low birth weight and maternal anemia. Int J Gynec Obst 121:103-9(https://doi.org/ 10.1016/j.ijgo.2012.12.014), Access date October 10, 2020. 2013:103-9.

3. WHO. Essential Nutrition Actions: IMPROVING MATERNAL, NEWBORN, INFANT AND YOUNG CHILD HEALTH AND NUTRITION, Geneva (https://apps.who.int/iris/handle/10665/84409), Access date October 10, 2020. $2013: 3-45$.

4. TheMANOFF GROUP(MOG). Guidance for Formative Research on Maternal Nutrition:Prepared for the Infant and Young Child Nutrition Project. . 2011:4-6.

5. TheMANOFF GROUP(MOG). Guidance for Formative Research on Maternal Nutrition:Prepared for the Infant and Young Child Nutrition Project(access date October 10, 2020). 2011:4-6.

6. Canavati SE, Zegers de Beyl, CLy P, Shafique M, Boukheng T, Rang C, et al. Evaluation of intensified behaviour change communication strategies in an artemisinin resistance setting. Malaria Journal, 15, 249. https://doi.org/10.1186/s12936-016-1276-8. 2016.

7. MIDDLETON PF, LASSI ZS, SON TRAN T, BHUTTA Z, BUBNER TK, FLENADY V, et al. Nutrition interventions and programs for reducing mortality and morbidity in pregnant and lactating women and women of reproductive age: $A$ systematic review Australian Research Centre for Health of Women and Babies (ARCH), Robinson Institute,The University of Adelaide 2013:20-30,.

8. WHO L. WHO recommendations on antenatal care for a positive pregnancy experience, ISBN 9789241549912. 2016.

9. TheMANOFF GROUP(MOG). Guidance for Formative Research on Maternal Nutrition:Prepared for the Infant and Young Child Nutrition Project(access date October 10, 2020). 2011:4-6 (access date October 10, 2020).

10. Oluwafolahan, Catherine, Olubukunola. Dietary Habits Of Pregnant Women In Ogun-East Senatorial Zone, Ogun State, Nigeria: A Comparative Stuudy. . International Journal Of Nutrition And Metabolism. 2014;6:42-9.

11. Hye-Kyung Oh, Sunjoo Kang, Sung-Hyun Cho, Yeong-ju Ju, Faye D. Factors influencing nutritional practices among mothers in Dakar, Senegal. PLOS ONE | https://doiorg/101371/journalpone0211787. 2019.

12. Victoria Q. Best practice in nutrition Repositioning Nutrition as Central to Development 2006:10-11.

13. USAID, WFP, FANTA 2 , FHi 360. Malnutrition in Uganda: Uganda Is Paying Too High a Price. 2010:13-15.

14. Shuayib Shemsu, Alemayehu Argaw, Beakal Zinab. Dietary Practice and Nutritional Status Among Pregnant Women Attending Antenatal Care at Mettu Karl Referral Hospital, Southwest Ethiopia. The Open Public Health Journal. $2020 ; 13$ 
15. Mahlet Yalewdeg, Mahlet Birhane, Yohannes Adissu. Dietary Practices and Their Determinants Among Pregnant Women in Gedeo Zone, Southern Ethiopia: A Community-Based Cross-Sectional Study. Dove Press journal: Nutrition and Dietary Supplements. 2020:12 267-275.

16. Federal Democratic Republic of Ehiopia, USAID. A Tool to Support Nutrition Advocacy in Ethiopia: Ethiopia PROFILES Estimates, Final Report. 2012:15-25.

17. Guyon A.B, V.J. Q. Essential nutrition action frame work. Training guide for health workers. Core Group, Washington DC. . 2011.

18. USAID/ENGINE, Save the children. MATERNAL DIET AND NUTRITION PRACTICES AND THEIR DETERMINANTS ENGINE: A project supported by the Feed the Future and Global Health Initiatives A report on formative research findings and recommendations for social and behavior change communication programming in the Amhara, Oromia, SNNP and Tigray regions of Ethiopia 2014:5-10.

19. USAID, JSI. Understanding the Essential Nutrition Actions and Essential Hygiene Actions Framework. 2015:1-5.

20. West Shoa Zone. West Shoa Zone, Health Office. 2015.

21. Fekadu B, Gemeda, Habtamu F, G W. Assessment of Knowledge and practice of Pregnant Mothers on Maternal Nutrition and Associated Factors in Guto Gida Woreda, East Wollega Zone, Ethiopia, J Nutrition \& Food Sciences. . 2015.

22. Morseda Chowdhury, Camille Raynes-Greenow, Ashraful Alam, Dibley MJ. Making a balanced plate for pregnant women to improve birthweight of infants: a study protocol for a cluster randomised controlled trial in rural Bangladesh. BMJ Open (http:// dx doi org/ 10 1136/ bmjopen- 2016-015393). 2017.

23. Farnoush Fallah, Ahmad Pourabbas, Ali Delpisheh, Yousef Veisani, Mahdi Shadnoush. Effects of Nutrition Education on Levels of Nutritional Awareness of Pregnant Women in Western Iran. International Journal of Endocrinology and Metabolism. 2013.

24. Lidia Ghirmai Teweldemedhin, Helen Gebretatyos Amanuel, Soliana Amanuel Berhe, Ghidey Gebreyohans, Zemenfes Tsige, Habte E. Effect of nutrition education by health professionals on pregnancy-specific nutrition knowledge and healthy dietary practice among pregnant women in Asmara, Eritrea: a quasiexperimental study(http://dx.doi.org/10.1136/bmjnph-2020-000159), . BMJ Nutrition, Prevention \& Health. 2021.

25. Tria Astika Endah Permatasari, Fauza Rizqiya, Walliyana Kusumaningati, Inne Indraaryani Suryaalamsah, Zahrofa Hermiwahyoeni. The effect of nutrition and reproductive health education of pregnant women in Indonesia using quasi experimental study. BMC Pregnancy and Childbirth https://doiorg/101186/s12884-021-03676-x. 2021; $21: 180$.

26. Rashid Abdi Guled, Nik Mazlan Bin Mamat, Wan Azdie Mohd Abu Bakar, Nega Assefa, Balachew T. Knowledge, Attitude and Practice of Mothers/caregivers on Infant and Young Child Feeding in Shabelle Zone, Somali Region, Eastern Ethiopia: A Cross Sectional Study. Revelation and Science. 2016; 06, No. 02 (1438H/2016) 42-54.

27. Samdal G.B., Eide G.E., Barth T., Williams G., Meland E. Effective behaviour change techniques for physical activity and healthy eating in overweight and obese adults; systematic review and meta-regression analyses. International Journal of Behavioral Nutrition and Physical Activity, 14, 42. https://doi.org/10.1186/s12966-017-0494-y. 2017. 
28. Beiguelman B, Colletto GMDD, Franchi-Pinto. Birthweight of twins, the fetal growth patterns of twins and singletons. Genet Mol Biol 1998;21:151-4.

29. Prince Kubi Appiah, Anang Rhoda Naa Korklu, Duut Abdulai Bonchel, Georgina Agartha Fenu, Francis WadgaMieza Yankey. Nutritional Knowledge and Dietary Intake Habits among Pregnant Adolescents Attending Antenatal Care Clinics in Urban Community in Ghana(https://doi.org/10.1155/2021/8835704). Journal of Nutrition and Metabolism. 2021; Volume 2021.

30. Hye-Kyung OhID, Sunjoo Kang, Sung-Hyun Cho, Yeong-ju Ju, Daouda Faye. Factors influencing nutritional practices among mothers in Dakar, Senegal (https://doi.org/10.1371/journal. pone.0211787). PLOSE ONE. 2019;14 (2).

31. Haji, Yemane, Alemayehu. Magnitude And Determinants Of Malnutrition Among Pregnant Women In Eastern Ethiopia: Evidence From Rural, Community-Based Setting Maternal And Child Nutrition. 2010.

32. Selemawit Asfaw Beyene, Lemlem Weldegerima, Freweini Gebrearegay Tela, Omer Seid, Amal Tucker Brown, Afework Mulugeta Bezabih. Barriers to utilize nutrition interventions among lactating women in rural communities of Tigray, northern Ethiopia: An exploratory study(https://doi.org/10.1371/journal.pone.0250696). PLOSE ONE. 2021;6(4).

33. Lonsako Abute, Abera Beyamo, Belay Erchafo, Tegegn Tadesse, Dawit Sulamo, Tagesse sadoro. Dietary Practice and Associated Factors among Pregnant Women in Misha Woreda, South Ethiopia: A Community-Based Cross-Sectional Study (https://doi.org/10.1155/2020/5091318). Journal of Nutrition and Metabolism. 2020;Volume 2020.

34. Zelalem T, Erdaw A, Tachbele E. Nutritional knowledge, attitude and practices among pregnant women who attend antenatal care at public hospitals of Addis Ababa, Ethiopia. International Journal of Nursing and Midwifery. 2018;10 (7) 81-9.

35. Yeshalem Mulugeta Demilew, Getu Degu Alene, Tefera Belachew. Dietary practices and associated factors among pregnant women in West Gojjam Zone, Northwest Ethiopia BMC Pregnancy and Childbirth. 2020;20(1):18.

\section{Figures}




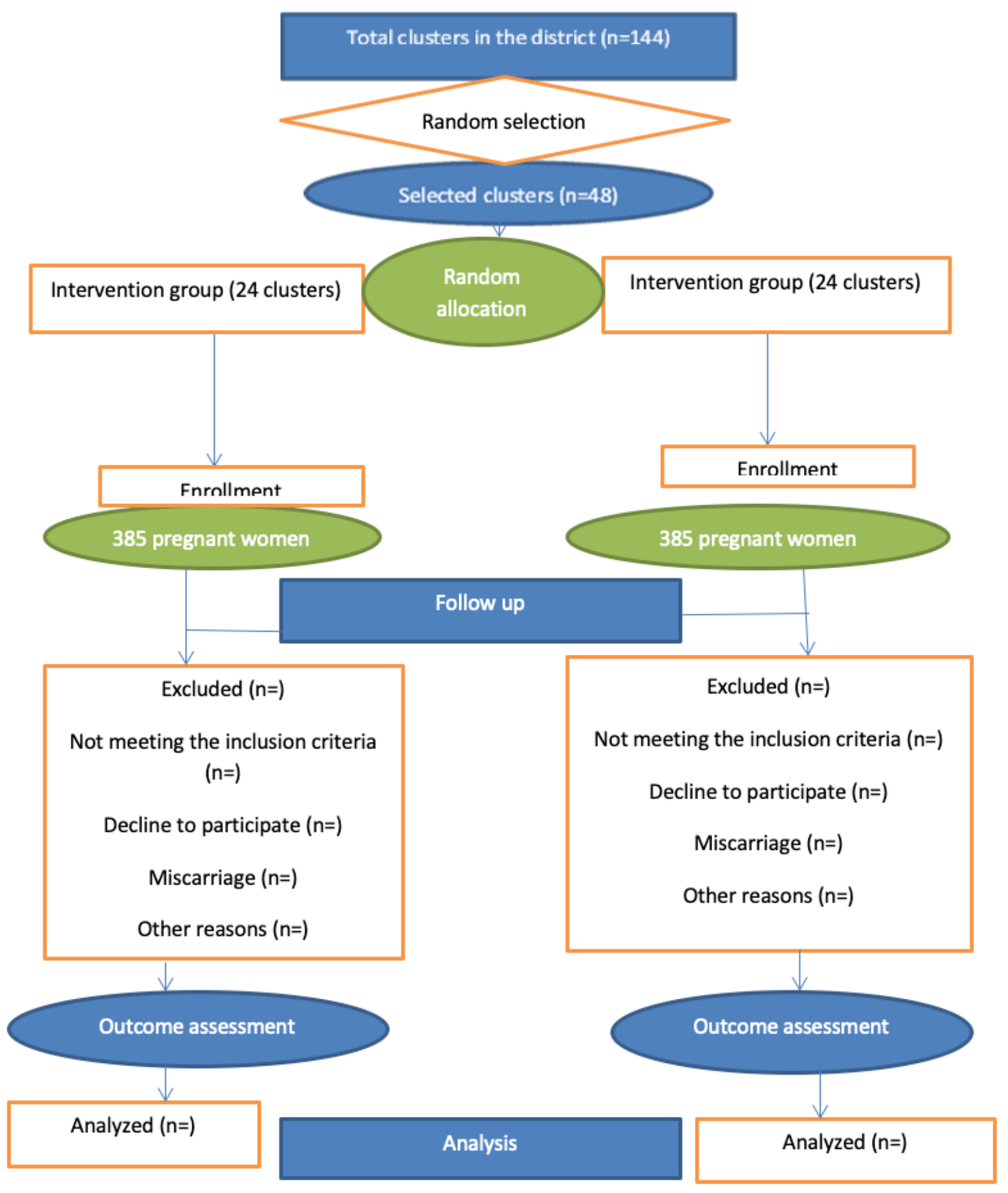

Figure 1

This figure shows the flow of the study participants through the trial, Ambo district, Ethiopia, 2018 


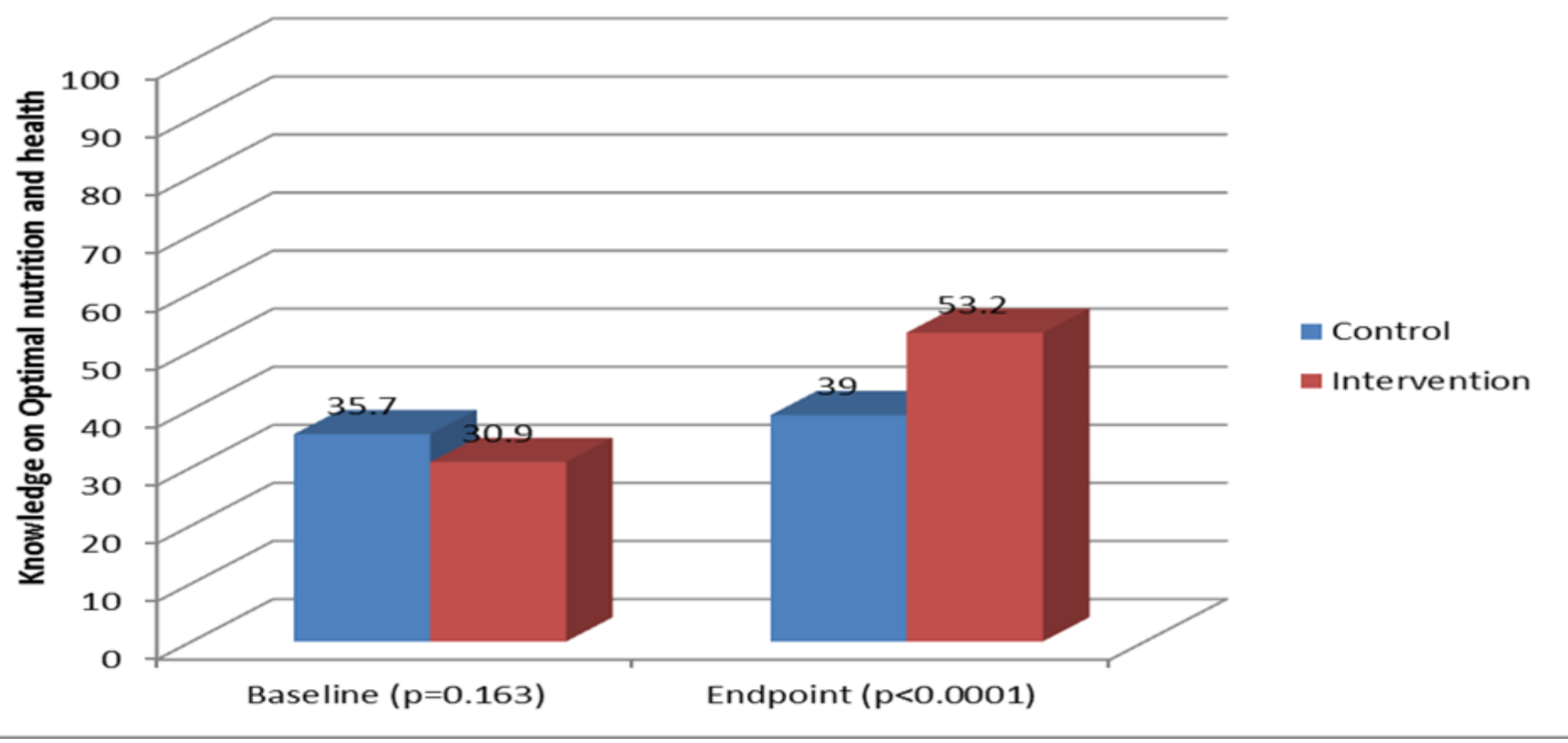

Figure 2

This figure shows knowledge on optimal nutrition and health at baseline and endpoint among intervention and control groups, Ambo district, Ethiopia, 2018

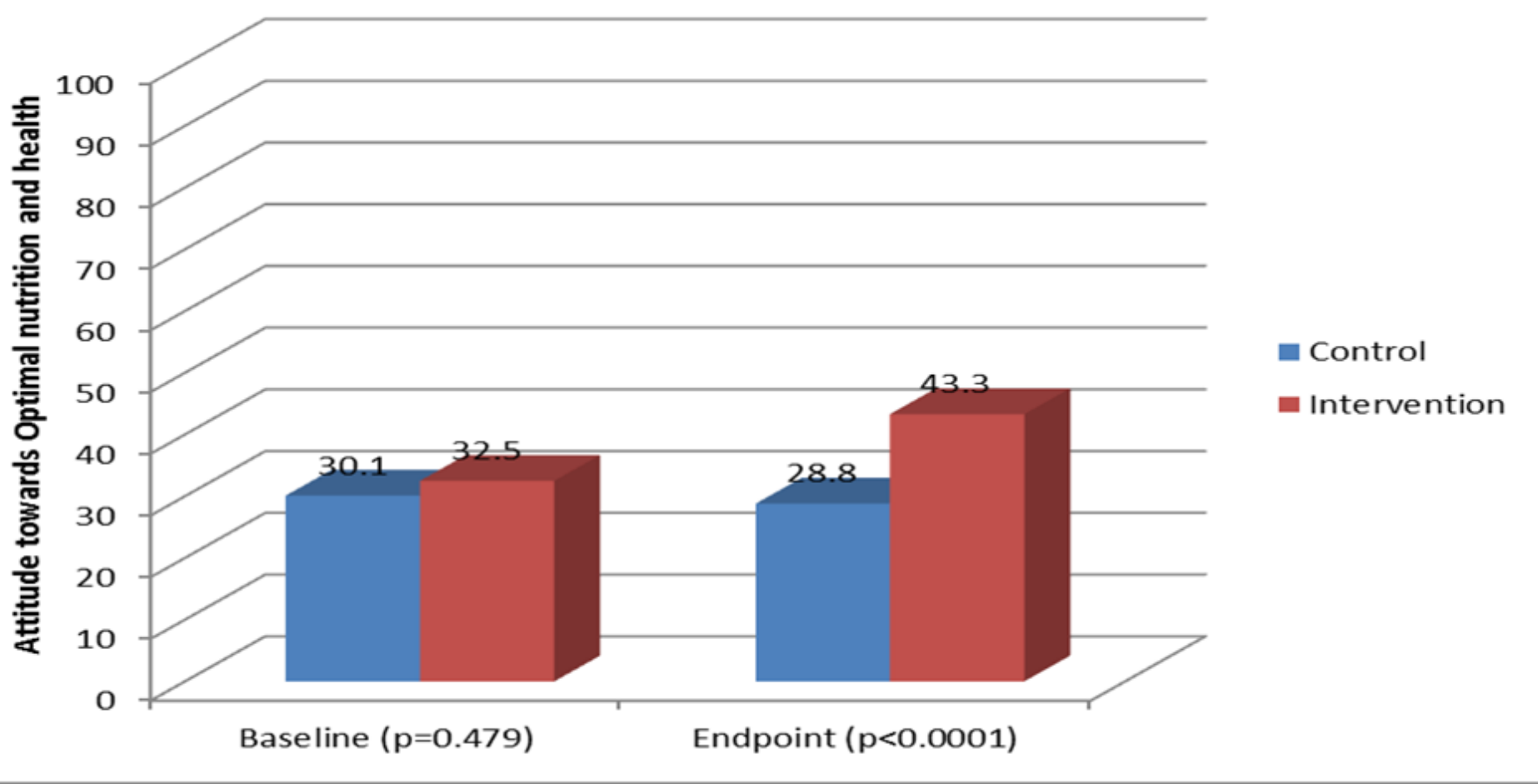

Figure 3

This figure shows attitude towards optimal nutrition and health at baseline and endpoint among intervention and control groups, Ambo district, Ethiopia, 2018 


\section{Supplementary Files}

This is a list of supplementary files associated with this preprint. Click to download.

- S1CONSORTChecklistadditonalfile2.docx 